\title{
LEVANTAMENTO DE SOLOS E INTERPRETAÇÃO FOTOGRÁFICA DOS PADRÕES DESENVOLVIDOS EM SOLOS ORIGINADOS DO ARENITO DE BAURU
}

\author{
G.V. de FRANÇA \\ Prof. Doutor do Dep. de Ciência do Solo da ESALQ/USP - Caixa Postal, 9 - CEP: 13418-900-Piracicaba,SP. \\ J.A.M. DEMATTÊ \\ Pós-Graduando do Curso de Ciência do Solo da ESALQUUSP - Caixa Postal, 9 - CEP: 13418-900-Piracicaba,SP.
}

\begin{abstract}
RESUMO: Com o auxilio de fotografias aéreas na escala 1:25.000, foram traçadas as redes de drenagen e posteriormente obtidos os parâmetros quantitativos necessários para a interpretação para fins pedológicos. A área estudada, com tamanho em torno de $700 \mathrm{~km}^{2}$ está Iocalizada no Oeste do Estado de São Paulo na região compreendida entre as cidades de Rancharia, Bastos, Tupã e Quatá, cortada pelo Rio do Peixe, cujo substrato é constituído pelo arenito de Bauru. Foi feito o estudo das bacias hidrográficas de terceira ordem de ramificação onde foram analisados o número, comprimento total e comprimento médio de segmentos de rios em amostras constituídas por bacias e por amostras circulares. Os valores da densidade de drenagem, principalmente das áreas circulares, mostraram serem parâmetros sensíveis na separação dos solos podzolizados abruptos dos solos latossólicos de textura média-arenosa. Além disso, esse parâmetro permitiu também separar os solos intermediários (PVL).

Descritores: levantamento de solos, fotointerpretação pedológica, densidade de drenagem.
\end{abstract}

\section{SOIL SURVEY AND PIOTOGRAPIIC INTERPRETATION OF DRAINAGE NETWORK FROM SOILS DEVEIOPED FROM BAURU SANDSTONE}

\begin{abstract}
ABSTR $\wedge$ CT: Drainage network and quantitative parameters necessary for pedologic interpretation were obtained by means of aerial photographs in the 1:25.000 scale. The study area has approximately $700 \mathrm{~km}^{2}$ and is located in the western part of Sao Paulo State. The rock substrate of the soils was identified as Bauru sandstone. The composition of drainage networks in watersheds was determined to the third order of ramification; drainage densities were determined by circular samples. Drainage density values showed differences between podzolic soils and the redyellow latosols. With the aid of this parameter it was possible to separate intergrade soil groups.
\end{abstract}

Key Words: soil survey, pedologic photointerpretation, drainage density.

\section{INTRODUÇÃO}

A região do Oeste do Estado de São Paulo é caracterizada por apresentar extensas áreas de solos de textura média a arenosa desenvolvidos de arenito de Bauru (BRASIL, 1960). Tal região tem apresentado grande desenvolvimento agrícola que, além da pecuária, está em expansão com as culturas de cana-de-açúcar, café e mais recentemente a cultura de citrus. Os trabalhos realizados na região a respeito da caracterização e mapeamento de solos são ainda escassos e executados em escala muito pequena como é o caso do levantamento de solos a nível de reconhecimento da Comissão de Solos (BRASIL, 1960) e que não se aplicam para planejamento agrícola a nível de maior detalhe. Tal trabalho destacou apenas três unidades de mapeamento em região de ocorrência do arenito de Bauru, sendo duas de solos podzolizados e uma de latossolo de textura média.
Em consequência desse fato, empresas ligadas à culturas aqui citadas, estão investindo em levantamento de solos, a níveis de maior detalhe, com as usinas e destilarias e as grandes empresas de citrus.

Nesse particular a interpretação folográfica é uma ferramenta poderosa e barata na geração de informações que auxiliam no mapeamento de solos. O padrão de drenagem superficial tem-se revelado como um dos mais úteis elementos de fotointerpretação para identificação dos solos e avaliação de sua natureza e propriedades.

A região éscolhida para esta pesquisa corresponde a uma área em torno de $700 \mathrm{~km}^{2}$ compreendida entre as cidades de Bastos, Tupã, Quatá e Rancharia, no Oeste do Estado de São Paulo e de interesse de um grupo empresarial desta região. Os principais objetivos pretendidos são os seguintes: 
- Executar o levantamento de solos a nível semi-detalhado na escala 1:25.000.

- Caracterizar os solos podzolizados, os solos intermediários e os latossolos de textura média-arenosa de acordo com os parâmetros fotográficos descritivos e quantitativos como indicado por LUEDER (1989) e FRANÇA (1968).

- Correlacionar os elementos fotopedológicos estudados para avaliar sua significância em relação à natureza dos solos.

\section{MATERIAL E MÉTODOS}

\section{Levantamento de Solos}

A área de estudo encontra-se no Sudocste do Estado de São Paulo (Figura 1) entre as cidades de Rancharia, Bastos, Tupã e Quatá, sendo cortada pelo Rio do Peixe, com uma extensão em torno dos $700 \mathrm{~km}^{2}$. O substrato é constituído pelo arenito de Bauru (ALMEIDA, 1964), o qual dá orıgnem aos solos podzolizados ou constituído de material retrabalhado desta própria rocha, originando os latossolos de textura média.

O mapeamento de solo executado e solicitado por uma empresa da reglão' foi o scmidetalhado tendo como apoio, folografias aéreas na escala 1:25.000, vôo da Terrafoto de 1972. Este trabalho foi feito no final de 1989 e consta do relatório interno da empresa ${ }^{1}$. Preliminarmente traçou-se toda a rede de drenagem nas fotografias e posteriormente com o auxílio dos resultados obtidos por FRANÇA \& DEMATTÊ (1990) e os demais padrões fotográficos (BURUNGH, 1960) foi traçado um primeiro esboço do mapa de solos. A seguir foram feitas amostragens de campo com o trado, num total de 320 pontos, numa densidade aproximada de 1 observação a cada 250 ha. As linhas de separação de solos foram ajustadas e posteriormente as unidades taxonômicas descritas, amostradas e enviadas para análise. As descrições morfológicas de solos foram baseadas no Manual para Descrição de Solos da Sociedade Brasileira de Ciência do Solo (1978).

A determinação granulométrica foi fcita pelo método do densímetro, em material disperso com $\mathrm{NaOH}$ (GROHMANN \& RAIJ, 1974); as

\section{Cia. Agrícola Quata}

Relatório sobre levantamento de solos da região de influência da Usina Quatá, 1990. determinações químicas foram executadas de acordo com a metodologia do Serviço Nacional de Levantamento e Conservação de Solos.

\section{Seleção das Áreas de Estudos e Parâmetros utilizados para Obtenção dos Dados}

Os solos foram classificados de acordo com os conccitos estabelecidos pela equipe de pedologia do Serviço Nacional de Levantamento e Conservação de Solos e, publicado em CAMARGO ct al. (1987).

Com o mapa de solos obtido, separou-se grupos de fotografias aćreas representativas das unidades de solo escolhidas e que portanto deveriam conter a informação desejada. Tomou-se o cuidado de selecionar amostras que contivessem as possível variações de solos.

Em relação aos solos podzolizados sclecionaram-sc quatro áreas, a sabcr:

Área 1: constituida por $90 \%$ de solos podzolizados abrúpticos e $10 \%$ de solos intermediários, PVL (Podzólico Vermelho Amarelo Latossólico). Associado aos solos podzolizados ocorrem cerca de $5 \%$ de Cambissolos de arenito

Área 2: área formada por $85 \%$ de solos podzolizados abrúpticos, $10 \%$ de solos podzolizados intermediários e $5 \%$ de latossolos de textura média.

Área 3. com $75 \%$ de solos podzolizados abrúpticos e $25 \%$ de solos intermediárıos, Podzólico Vermelho Amarelo Latossólico (PVL).

Área 4: com $65 \%$ de solos podzolizados abrúpticos, $25 \%$ de solos intermediários (PVL) e $10 \%$ de latossolos de textura média.

Em relação à regiões de textura médiaarenosa também foram selecionadas 4 áreas. Todas elas são representadas por $100 \%$ de latossolos de textura média. A única excessão é a área 4, que se apresenta associada ao latossolo $15 \%$ de Areias Quatzosas. Para os solos intermediários foram sclecionadas duas árcas.

A rede de drenagem foi traçada com o auxílio de estereoscópio e transferida em papel transparente fixado em cada fotografia aérea 


\section{CARACTERIZAÇAO DA AREA}

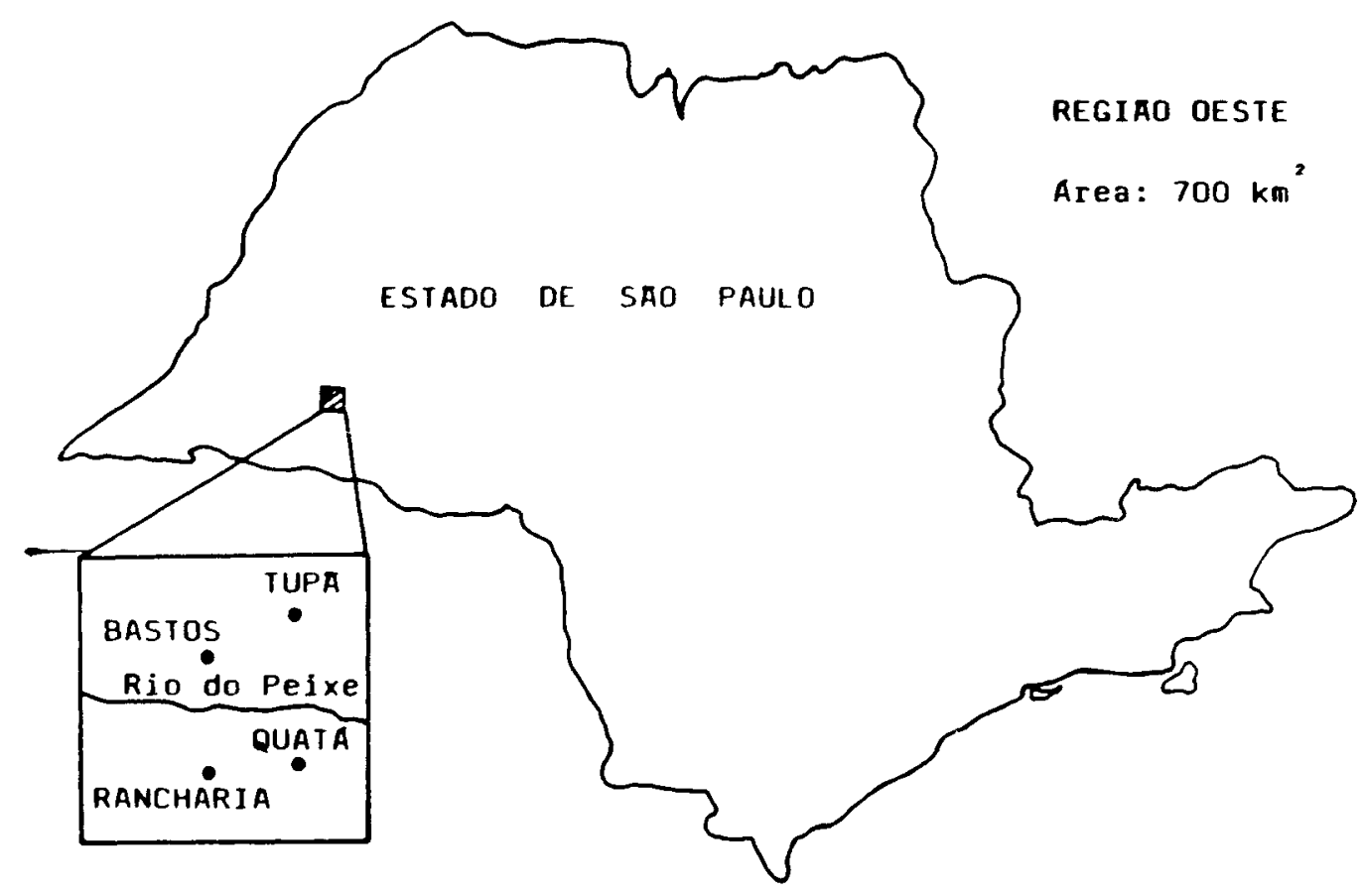

Figura 1 - Locálização da áréa de estudo em relaçào ao Estado de São Paulo

empregada a seguir fic-se a montagem completa dessc traçado, oblendo assım um mapa geral dadrenagem Traçaram-se entào os limites das áreas de solo utılizando-se a carta de solos da região Sobre este mapa foram delimitadas otto bacias hidrográficas de tamanhos varávess, com seus respectivos divisores de água, porém da mesma ordem de rios, no caso de $3^{d}$ ordem e olto amostras circulares de $10 \mathrm{~km}^{2}$ nas áreas correspondentes a cada bacia, para posterior comparação entre os doss métodos de obtenção de densidade de drenagem.

Nos mapas de drenagem procedeu-se inicialmente à análise das bacias hidrográficas, no seguintes aspectos:

- Representatividade: expressa em termos de porcentagem da área total da bacia, ocupada pelo solo predominante.
- Desenvolvimento longitudinal, ou comprimento do curso principal, medido com curvímetro, acompanhando as sinuosidades do no principal, da for até a nascente

- Perímetro expresso pelo comprimento da linha do divisor de água que circula a bacia, medido por curvímetro

Após estes estudos procedeu-se à análıse das respectivas redes de drenagem de acordo com especıficações de STRAHLER (1957), a saber.

- Ordem de ramificação os segmentos de nos foram classificados com base na ordem de ramificação

- Número de segmentos de rios: foram obtidos os segmentos de rios $\mathrm{cm}$ cada ordem e o total da 
bacia. $O$ símbolo $w$ foi utilizado para uma dada ordem de ramificação, o Nw para o número de segmentos de cada ordem e o $\mathrm{Nt}$ para o número total de segmentos da bacia.

- Comprimento dos rios; por meio de um curvímetro foram determinados diversos valores, a saber:

$\mathbf{w}=$ ordem da bacia

$\mathrm{Lw}=$ soma dos comprimentos de segmentos de rios em cada ordem.

$\mathrm{Lt}=$ comprimento total de todos os rios de uma bacia.

Im = comprimento médio de segmentos de rios, obtidos da divisão do Lw pelo Nw.

O padrão de drenagem individual de cada unidade representativa de solos inclui a frequência de rios, a densidade de drenagem e a razão de textura. Entretanto, para representar o padrão de drenagem como um todo, foram determinadas as seguintes características quantitativas, a saber:

- A textura de drenagem $T$, expressa pela razão entre o número de crênulas $\mathrm{N}$ na curva de nível, e o perímetro $\mathrm{P}$ da bacia. Para tanto usou-se as folhas do IBGE, escala 1:50.000.

- Razão de textura média (Tm), obtida pela expressão.

$$
\mathrm{Tm}=(\mathrm{A} \cdot \mathrm{T}) / \mathrm{A}
$$

onde: $\mathrm{A}$ representa a área e $\mathrm{T}$ a razão de textura de cada bacia.

- Amostras circulares: foi utilizado o método de amostragem proposto por RAY \& FISCHER (1960), o qual consiste na tomada de amostras circulares homogêneas com área de $10 \mathrm{Km}^{2}$.

\section{RESULTADOS E DISCUSSÃO}

\section{Levantamento de Solos}

O levantamento pedológico semidetalhado cobriu uma área aproximada de $700 \mathrm{Km}^{2}$ compreendida entre as regiões de Bastos, Tupã, Quatá e Rancharia, situado no Sudoeste do Estado de São Paulo. O clima segundo Koppen é Cwa, tropical de altitude com inverno seco. O índice pluviométrico varia entre $1.100 \mathrm{e} 1.700 \mathrm{~mm}$ anuais e a estação seca ocorre entre os meses de abril a setembro. A temperatura do mês mais quente oscila entre $22 \mathrm{e} 24^{\circ} \mathrm{C}$. O material de origem é resultado do intemperismo do arenito de Bauru, com ou sem cimento calcário. De acordo com BRASIL (1960), a Séric Bauru dá origem a diferentes solos. Quando o arenito apresenta cimento calcário os solos são mais férteis, têm saturação de bases alta, ocorrendo em relevo ondulado e sendo encontrados com mais frequência nas unidades de mapeamento, Solos Podzolizados de Lins e Marilia, além do latossol correspondente. Quando o cimento que consolida os grãos de quartzo não é calcário, os solos são mais ácidos e menos férteis, ocorrendo em relevo mais plano dando a unidade Latossolo Vermelho Escuro fase arenosa. Foram identificadas 9 unidades taxonômicas cujas características se encontram na TABELA 1 . Segundo OLIVEIRA et al. (1979), os regimes hídrico e térmico do solo dessa região são respectivamente, o ústıco e o 1sohipertérmico. Os solos podzolizados (unidades $\mathrm{PV}_{1}, \mathrm{PV}_{2}$ e $\mathrm{PV}_{3}$ ) apresentam horizontes de textura contrastante, areia na superfícic e média no horizonte B textural, profundidade variável, 2 a 3 metros, bem drenados na superfícic e drenagem moderada no B. Quimicamente são solos de fertilidade variável indo desde os solos bem saturados, como os eutróficos da unidade $\mathrm{PV}_{1}$ aos desaturados e álicos das unidades $\mathrm{PV}_{2} \mathrm{e} \mathrm{PV}_{3} \mathrm{De}$ modo geral, estas unidades correspondem aos Solos Podzolizados, variação Marilia ou Lins (BRASIL, 1960). Diferem entretanto, no aspecto químico.

Das unidades aqui descritas somente os perfis correspondentes à unidade $P V_{1}$ correspondem às variações Lins ou Marilia, apesar das unidades $\mathrm{PV}_{2}$ e $\mathrm{PV}_{3}$ serem morfologicamente semelhantes à unidade $\mathrm{PV}_{1}$. A ocorrência de solos podzolizados desaturados no Oeste do Estado de São Paulo não foi descrita por BRASIL (1960). Tudo indica, entretanto, que este fato não é incomum $\mathrm{Em}$ trabalho feito na região de Matão(SF), DEMATTÊ (1979), identificava solos podzolizados desaturados, descritos por QUEIROZ NETO \& JOURNAUX (1978). Tudo indica que a ocorrência destes solos se deve provavelmente à bolsões, dentro do arenito Bauru, com pouco ou nenhum cimento calcário. Em termos de topografia as três unidades aqui descritas ocorrem nas encostas, em relevo bem dissecado e ondulado. As unidades $\mathrm{PV}_{2}$ e $\mathrm{PV}_{3}$ de maneira geral ocupam posições no relevo ligeiramente superior à unidade $\mathrm{PV}_{1}$, está sempre associada com o Cambissolo de Arenito. 
TABELA 1 - Características granulométricas e químicas de perfis selecionados.

\begin{tabular}{|c|c|c|c|c|c|c|c|c|}
\hline \multirow{2}{*}{$\begin{array}{l}\text { Uni- } \\
\text { dade }\end{array}$} & \multirow{2}{*}{$\begin{array}{l}\text { Hori- } \\
\text { zonte }\end{array}$} & \multirow{2}{*}{$\begin{array}{l}\text { Profundi- } \\
\text { dade }(\mathrm{cm})\end{array}$} & \multicolumn{3}{|c|}{ Granulometria (\%) } & \multirow{2}{*}{$\begin{array}{c}\mathrm{pH} \\
\mathrm{CaCl}_{2} \\
\end{array}$} & \multirow{2}{*}{$\begin{array}{c}\text { MO } \\
\% \\
\end{array}$} & \multirow{2}{*}{$\begin{array}{r}\mathbf{P} \\
\mathrm{ppm}\end{array}$} \\
\hline & & & areia & silte & argila & & & \\
\hline \multicolumn{9}{|c|}{ Podzólico Vermelho Amarelo Eutrófico (Perfil 25) } \\
\hline & Ap & $0-15$ & 87 & 1 & 12 & 6,0 & 1,0 & 11 \\
\hline $\mathrm{PV}_{1}$ & $\mathrm{E}$ & 60 & 91 & 1 & 8 & 6,1 & 0,7 & 7 \\
\hline$(7 \%)$ & $\mathrm{Bt}$ & 110 & 74 & 1 & 25 & 5,9 & 0,9 & 2 \\
\hline \multicolumn{9}{|c|}{ Podzólico Vermelho Amarclo Distrófico (Perfil 11) } \\
\hline & Ap & $0-28$ & 88 & 1 & 11 & 5,2 & 1,7 & 8 \\
\hline $\mathrm{PV}_{2}$ & $\mathrm{E}$ & 65 & 88 & 2 & 10 & 4,8 & 1,2 & 1 \\
\hline$(10 \%)$ & $\mathrm{Bt}$ & 110 & 80 & 1 & 19 & 4,4 & 1,2 & 1 \\
\hline \multicolumn{9}{|c|}{ Podzólıco Vermelho Amarelo Álıco (Perfil 30) } \\
\hline & Ap & $0-10$ & 86 & 1 & 13 & 4,7 & 1,2 & 6 \\
\hline $\mathrm{PV}_{3}$ & E & 40 & 89 & 1 & 10 & 4,8 & 1,0 & 5 \\
\hline$(8 \%)$ & $\mathrm{Bt}$ & 90 & 76 & 3 & 21 & 4,7 & 0,9 & 1 \\
\hline \multicolumn{9}{|c|}{ Podzólico Vermelho Amarelo Latossólico Distrófico (Perfil 59) } \\
\hline & Ap & $0-15$ & 84 & 2 & 14 & 4,3 & 1,2 & 3 \\
\hline $\mathrm{PV}_{4}$ & $\mathrm{Bt}$ & 60 & 79 & 3 & 18 & 4,2 & 1,0 & 1 \\
\hline$(20 \%)$ & $\mathrm{Bw}$ & 140 & 77 & 2 & 21 & 4,2 & 0,6 & 1 \\
\hline \multicolumn{9}{|c|}{ Latossolo Vermelho Escuro Textura Média (teor Argila 15-25\%), Álico } \\
\hline & Ap & $0-20$ & 82 & 1 & 17 & 4,3 & 2,0 & 4 \\
\hline $\mathrm{LE}_{1}$ & A3 & 60 & 81 & 1 & 18 & 3,9 & 1,9 & 2 \\
\hline$(43 \%)$ & Bw & 100 & 75 & 2 & 23 & 3,8 & 1,7 & 1 \\
\hline \multicolumn{9}{|c|}{ Latossolo Vermelho Escuro Texlura Médıa (teor Argila 25-35\%), distrófico (Perfil 8) } \\
\hline & Ap & $0-25$ & 77 & 2 & 21 & 5,0 & 1,9 & 18 \\
\hline $\mathrm{LE}_{2}$ & A3 & 50 & 71 & 4 & 25 & 4,1 & 1,4 & 4 \\
\hline$(12 \%)$ & $\mathrm{Bw}$ & 110 & 68 & 1 & 31 & 4,0 & 1,2 & 1 \\
\hline
\end{tabular}

Valores entre parêntesis representam a porcentagem de ocorrência das unidades de mapcamento

Independentemente do caráler de saturação de bases, o teor de potássio destas unidades de solo é médio a alto, sempre superior a
$3 \%$ da capacidade de troca catıônica. Devido à variaçâo textural elevada, a diferença de drenagem entre os horizontes e o relevo ondulado, estcs solos 
TABELA 1 - Características granulométricas e químicas de perfis selecionados. (Continuação).

\begin{tabular}{|c|c|c|c|c|c|c|c|c|}
\hline \multirow{2}{*}{$\begin{array}{l}\text { Uni- } \\
\text { dade }\end{array}$} & $\mathbf{K}$ & $\mathrm{Ca}$ & $\mathbf{M g}$ & Al & SB & CTC & V & $\mathrm{Al}$ \\
\hline & \multicolumn{5}{|c|}{ e.mg/100 g solo } & & \multicolumn{2}{|c|}{$\%$} \\
\hline \multicolumn{9}{|c|}{ Podzólico Vermelho Amarelo Eutrófico (Perfil 25) } \\
\hline & 0,12 & 0,83 & 0,45 & 0,16 & 1,40 & 2,2 & 64 & 10 \\
\hline $\mathrm{PV}_{1}$ & 0,16 & 0,76 & 0,37 & 0,10 & 1,29 & 2,1 & 62 & 7 \\
\hline$(7 \%)$ & 0,18 & 0,65 & 0,33 & 0,10 & 1,05 & 2,1 & 51 & 2 \\
\hline \multicolumn{9}{|c|}{ Podzólico Vermelho Amarelo Distrófico (Perfil 11) } \\
\hline & 0,18 & 0,79 & 0,28 & 0,10 & 1,25 & 2,75 & 45 & 7 \\
\hline $\mathrm{PV}_{2}$ & 0,15 & 0,51 & 0,17 & 0,14 & 0,83 & 2,13 & 39 & 14 \\
\hline$(10 \%)$ & 0,18 & 0,83 & 0,28 & 0,34 & 1,29 & 3,29 & 39 & 20 \\
\hline \multicolumn{9}{|c|}{ Podzólico Vermelho Amarelo Álico (Perfil 30) } \\
\hline & 0,17 & 0,82 & 0,27 & 0,30 & 1,26 & 2,86 & 44 & 19 \\
\hline $\mathrm{PV}_{3}$ & 0,19 & 0,36 & 0,15 & 0,18 & 0,70 & 2,30 & 30 & 20 \\
\hline$(8 \%)$ & 0,23 & 0,46 & 0,17 & 1,70 & 0,86 & 4,26 & 15 & 66 \\
\hline \multicolumn{9}{|c|}{ Podzólico Vermelho Amarelo Latossólico Distrófico (Perfil 59) } \\
\hline & 0,40 & 0,59 & 0,26 & 0,42 & 1,3 & 4,1 & 31 & 74 \\
\hline $\mathrm{PV}_{4}$ & 0,10 & 0,83 & 0,33 & 0,71 & 1,3 & 4,4 & 30 & 64 \\
\hline$(20 \%)$ & 0,02 & 0,77 & 0,05 & 1,20 & 0,8 & 4,4 & 21 & 41 \\
\hline \multicolumn{9}{|c|}{ Latossolo Vermelho Escuro Textura Média (teor Argila 15-25\%), Álico } \\
\hline & 0,15 & 0,38 & 0,29 & 0,54 & 0,82 & 3,32 & 25 & 40 \\
\hline $\mathrm{LE}_{1}$ & 0,10 & 0,09 & 0,10 & 0,90 & 0,29 & 3,09 & 9 & 76 \\
\hline$(43 \%)$ & 0,06 & 0,08 & 0,07 & 1,40 & 0,21 & 3,61 & 6 & 83 \\
\hline \multicolumn{9}{|c|}{ Latossolo Vermelho Escuro Textura Média (teor Argila 25-35\%), distrófico (Perfil 8) } \\
\hline & 0,10 & 1,40 & 0,25 & 0,16 & 1,75 & 3,95 & 44 & 8 \\
\hline $\mathbf{L E}_{2}$ & 0,08 & 0,66 & 0,11 & 0,80 & 0,85 & 4,25 & 20 & 49 \\
\hline$(12 \%)$ & 0,04 & 0,71 & 0,26 & 0,90 & 1,01 & 4,41 & 23 & 47 \\
\hline
\end{tabular}

Valores entre parêntesis representam a porcentagem de ocorrência das unidades de mapeamento.

são muito suscetíveis à erosão.

O outrồ grupo de solos é constituído por duas unidades de mapeamento, caracterizadas como
Latossolo Vermelho Escuro, ambos de textura média. São solos profundos, uniformes em textura, com teor de argila no B entre 15 e $25 \%$ (Unidade 
$L_{1}$ ) e entre $25 \%$ e $35 \%$ (Unidade $L_{2}$ ). São bem drenados tanto na superfície como na subsuperfície e de baixa fertilidade. De maneira geral, são distróficos ou álicos. Ocorrem nas partes altas, em relevo plano e suavemente ondulado, pouco dissecado.

Entre os dois grupos de solos dominantes o PV com $25 \%$ e o LE com $55 \%$, ocorre um terceiro grupo de solos intermediários. Granulometricamente são solos com menor gradiente textural do que os PV típicos mantendo entretanto transição gradual entre o A e o B. Não ocorre horizonte álbico e logo após o pequeno horizonte argílico ocorre o horizonte $B$ latossólico. A drenagem no horizonte $B$ já é bem melhor do que os $\mathrm{PV}$, porém havendo ainda risco de encharcamento. Quimicamente são solos ligeiramente distróficos, com saturação de bases entre 0 e $40 \%$ e raramente álicos. Na paisagem podem ser considerados como solos transicionais entre os $\mathrm{PV}_{2} \mathrm{e}$ os $\mathrm{LE}_{3}$, com relevo ondulado e pouco dissecado.

\section{Parâmetros das Redes de Drenagem}

Os resultados dos principais parâmetros das redes de drenagem para as 10 áreas estudadas estão indicados na TABELA 2 Os valores das densidades de drenagem apresentam uma variação entre 3,40 e 5,27 para os solos podzolizados e uma variação de menor amplitude para os casos dos latossolos de textura média, a saber: 1,06 e 1,64. No caso específico dos $\mathrm{LE}_{\mathrm{m}}$ há redução do valor da densidade de drenagem à medida que aparecem: as Areias Quartzosas como inclusão, ou seja, os valores da densidade de drenagem estão na faixa de 1,6 para o $\mathrm{LE}_{\mathrm{m}}$ e de 1,0 para as AQ (Figura 2). Como se verifica, os valores das densidades de drenagem das bacias do $L E_{m}$ refletem a dominância da drenagem dos solos. Qualquer alteração na drenagem interna dos solos reflete alteração na densidade de drenagem, ou seja, as AQ drenam melhor do que os $\mathrm{LE}_{\mathrm{m}}$. Em consequência disto a área da bacia é maior no caso $4,14 \mathrm{Km}^{2}$ para a $\mathrm{AQ}$ e valores entre 2,7 e 3,4 para o $\mathrm{LE}_{\mathrm{m}}$.

O mesmo tem ocorrido com os solos podzolizados. Assim é que a amostra 1, menor área da bacia, $0,36 \mathrm{Km}^{2}$, bastante dissecada, corresponde a mais elevada densidade de drenagem, 5,27, enquanto que a amostra 3 , de maior bacia, $0,90 \mathrm{Km}^{2}$ corresponde à menor densidade de drenagem, no caso 3,40. Tais valores refletem a drenagem interna dos solos. Enquanto que na amostra 1 domina o PVA abruptico associado aos solos litólicos, portanto, de drenagem interna mais restrita, na amostra 3 domina apenas os PVA abrúpticos com poucas inclusões dos PVL de melhor drenagem.

Para o caso dos PVL, amostras 9 e 10 da TABELA 2, os padrões de densidade de drenagem têm-se mostrado com valores intermediários. A densidade de drenagem, neste caso, está na faixa de 3,25 contra um valor médio de 4,55 para os PV abrúpticos e 1,17 para os latossolos. As áreas das bacias acompanham esta mesma tendência. Como já foi salientado os PVL são solos de melhor drenagem do que os PV abrúpticos. Entretanto, a presença de um horizonte $B t$ de pequena expessura sobre um Bw nos perfis de PVL é suficiente para obter uma drenagem interna mais restrita do que nos $L_{\mathrm{m}}$.

Por outro lado a densidade de drenagem para amostras circulares, onde se mantém constante a área, no caso $10 \mathrm{Km}^{2}$, refletem melhor a questão das inclusões do que as amostras das bacias. Para o caso dos solos podzolizados, amostras 1 a 4 , a porcentagem de inclusão, principalmente do PVL, aumenta neste sentido de 10 a 25\% (TABELA 2). A densidade de drenagem passa de 5,7 para a amostra 1, mais dissecada, para 4,5 na amostra 4, com 25\% de inclusão. Para o caso dos solos latossólicos, a variação de densidade de drenagem é bem menor, na faixa média de 0,62 , refletindo, com isso a maior uniformidade da área, e também maior profundidade do material geológico (Figura $3)$.

No caso dos Podzólicos Vermelho Amarelo Latossólicos, os valores da densidade de drenagem estão na faixa dos 2,11. Intermediários entre os solos de melhor drenagem no caso os $L_{\mathrm{m}}$ com os solos de pior drenagem interna (TABELA 2), no caso os PV abrúpticos.

Os valores da densidade de drenagem dos PVA abruptos aqui encontrados são ligeiramente superiores aos encontrados por KOFFLER (1976), que também trabalhou com os solos desenvolvidos do arenito de Bauru, inclusive para os solos intermediários. Tal fato se deve provavelmente à escala utilizada para os mapas de solos. Enquanto aquele autor usou mapa de solos na escala 1:500.000 o trabalho aqui apresentado se utilizou de mapa de solos na escala 1:25.000, de maior precisão.

Por outro lado, os valores de densidade de drenagem encontrados por FRANÇA \& DEMATTÊ (1990) em solos desenvolvidos de 

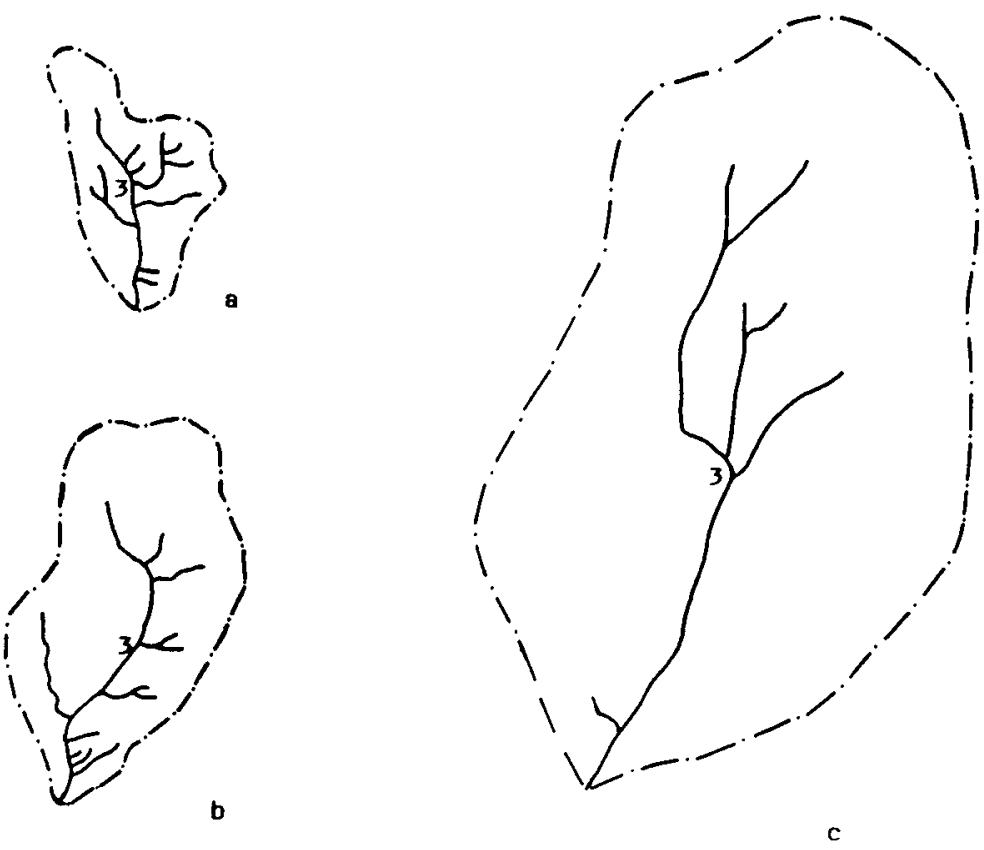

Figura 2 - Rede de drenagem das bacias estudadas

a) Área 1, PV abrupto e Dd $=5,27$

b) Área 3, PV abrupto e Dd $=3.40$

c) Área 8, LEm c Dd $=1,06$
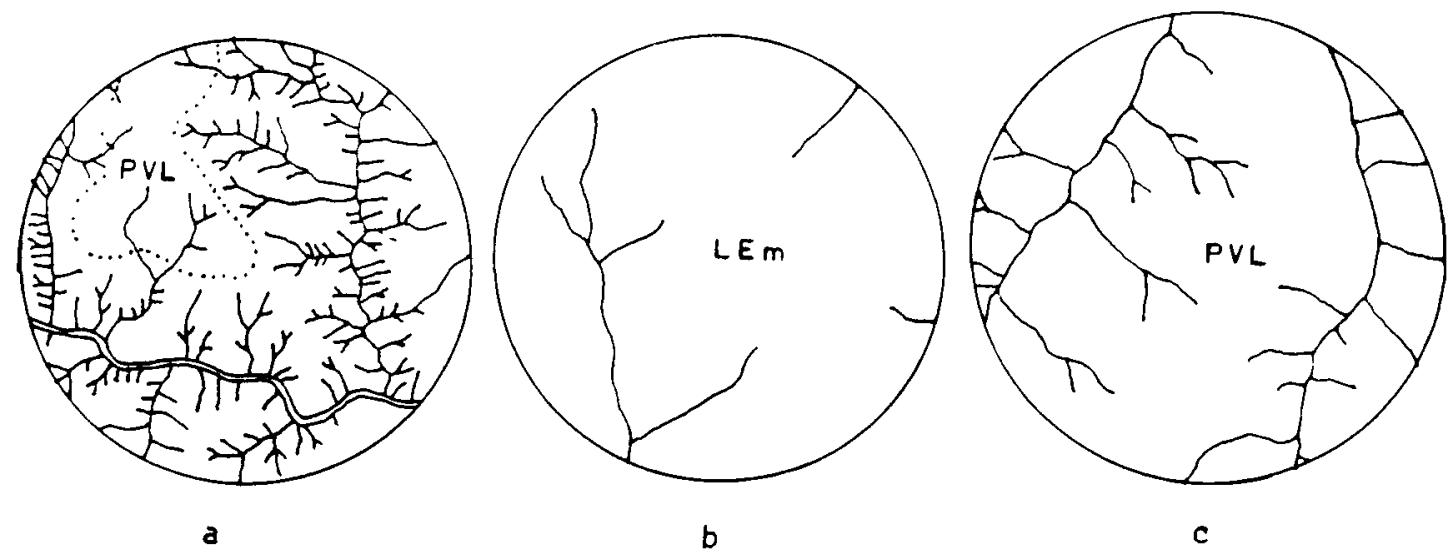

Figura 3 - Densidade de drenagem em amostras circulares.

a) Área 1, com $90 \%$ de PVA abrupto

b) Área 5, com $100 \%$ de LEm

c) Área 7, com $100 \%$ de PVL.

Sci. agric. Piracicaba. 50(1):77-86, fev./maio, 1993 
TABELA 2 - Resultados de densidade de drenagem para bacias e amostras circulares, frequência de rios e textura de drenagem nos solos de ocorrência na área de estudo.

\begin{tabular}{cccccccccccc}
\hline \hline ASS & I (\%) & Lt $(\mathrm{km})$ & Área $\mathrm{Km}^{2}$ & DDB & Lt $(\mathrm{Km})$ & DDAC & Nw & FR & P (Km) & TD \\
\hline \multicolumn{7}{c}{ Podzólico Vermelho amarelo Textura Areia/Média } \\
1 & 10 & 1,90 & 0,36 & 5,27 & 57,0 & 5,7 & 11 & 30,5 & 2,5 & 4,4 \\
2 & 15 & 3,75 & 0,84 & 4,46 & 51,8 & 5,2 & 14 & 16,6 & 3,9 & 3,6 \\
3 & 20 & 3,10 & 0,90 & 3,40 & 47,0 & 4,7 & 12 & 13,3 & 3,7 & 3,2 \\
4 & 25 & 2,8 & 0,55 & 5,08 & 45,0 & 4,5 & 8 & 14,5 & 3,1 & 2,6 \\
\multicolumn{2}{|c}{ média } & & 0,66 & 4,55 & & 5,0 & & & &
\end{tabular}

Latossol Vermelho Escuro Textura Média

\begin{tabular}{lllllllllll}
5 & - & 4,4 & 2,73 & 1,61 & 6,7 & 0,67 & 4 & 1,46 & 6,7 & 0,59 \\
6 & - & 4,8 & 2,95 & 1,63 & 7,0 & 0,70 & 7 & 2,37 & 6,7 & 1,04 \\
7 & - & 5,7 & 3,46 & 1,64 & 4,8 & 0,48 & 9 & 2,60 & 8,0 & 1,12 \\
8 & 15 & 4,4 & 4,14 & 1,06 & 6,3 & 0,63 & 6 & 1,45 & 7,6 & 0,79 \\
\multicolumn{2}{l}{ média } & & 3,32 & 1,27 & & 0,62 & & & &
\end{tabular}

Podzólico Vermelho Amarclo Latossólico Textura Areia/Média

\begin{tabular}{llllllllll}
9 & 4,4 & 1,39 & 3,28 & 22,5 & 2,25 & 9 & 4,48 & 4,2 & 2,1 \\
10 & 2,9 & 0,90 & 3,23 & 20,2 & 2,02 & 13 & 11.1 & 4,7 & 2,7 \\
média & & 1,14 & 3,25 & 2,11 & & & & & \\
\hline \hline
\end{tabular}

ASS = Amostra sclecionada no mapa de solos.

$\mathrm{Lt}=$ Comprimento total de todos os rios da bacia

$\mathrm{Nw}=$ Número de segmentos de cada ordem de rio

$\mathrm{FR}=$ Frequência de rios

$\mathrm{TD}=$ Textura de drenagem
$\mathrm{I}=$ Inclusão de outros solos

DDB $=$ Densidade de drenagem em bacias

DDAC $=$ Densidadede drenagem em área circular $\mathbf{P}=$ Perímetro arenitos c/ou siltitos da formação Tubarão, estão na faixa 3,63 a 4,53 , ligeiramente inferiores aos aqui encontrados. Tais diferenças se devem à natureza do matcrial de origem. Aparentemente os arenitos da formação Tubarão são mais permcáveis do que os arenitos do Grupo Bauru, haja visto que as áreas dos solos podzolizados estudados por FRANÇA \& DEMATTÊ (1990), são menos dissecados do que as áreas dos PV abrúpticos da região Oeste do Estado de São Paulo. No caso dos latossolos, tais autores encontraram valores entre 1,00 a 1,15 , superiores aos aqui encontrados, no caso valor médio de 0,62 . Também neste caso, as variações dos valores superiores da densidade de drenagem encontrada por aqueles autores para os latossolos se deve à natureza mais argilosa do material de origem. Em consequêneia disto, a drenagem interna dos latossolos estudados por tais autores, é menor do que os latossolos arenosos da região aqui estudada, e consequentemente, o relevo é pouco mais dissecado.

A razão da textura reflete bem os grupos de solo estudados, sendo que para os PV abrúpticos, a razão de textura pode ser classificada como média enquanto que para os $\mathrm{LE}_{\mathrm{m}}$ é grosseira. 


\section{CONCLUSOES}

Os PV abrúpticos são constituídos quimicamente por solos eutróficos, distróficos e álicos. Os valores da densidade de drenagem, tanto das amostras de bacias, como circulares, se mostraram seguras na separação dos Grupos de Solos. Em especial a densidade de drenagem das amostras circulares, foi ainda mais sensível, inclusive na separação das porcentagens das inclusões dentro da unidade PV abrúptico.

\section{REFERÊNCIAS BIBLIOGRÁFICAS}

ALMEIDA, F.F.M. Fundamentos geológicos do relevo paulista. In: INSTITUTO GEOGRÁFICO E GEOLÓGICO. Geologia do Estado de São Paulo. São Paulo, 1964. p.167-262. (IGG. Boletim, 41).

BRASIL. Ministério da Agricultura. Centro Nacional de Pesquisas Agronômicas. Serviço Nacional de Pesquisas Agronômicas. Levantamento de reconhecimento dos solos do Estado de São Paulo. Rio de Janciro, 1960. 634p. (Boletim, 12).

BURUNGH, $P$. The application of aerial photography in soils surveys. In: AMERICAN SOCIETY OF FOTOGRAMMETRY. Manual of plotography interpretation. Washington, 1960. p.633-636.

CAMARGO, M.N.; KLANT, E.; KONFFMAN, J.H. Sistema Brasileiro de Classificação de Solos. Boletim Informativo da Sociedade Brasileira de Ciência do Solo. Campinas, v.12, n.1, p.11-33, 1987.

DEMATTÊ, J.L.I. Levantamento semi-detalhado da Fazenda Cambuí,SP. Piracicaba : ESALQ, Depto. de Solos, 1979. 85p.

FRANÇA, G.V. Interpretação fotográfica de bacias e de redes de drenagem aplicadas a solos da regiâo de Piracicaba. 1968, 151p. Tese (Doutorado) - Escola Superior de Agricultura "Luiz de Queiroz", Universidade de São Paulo.
FRANÇA, G.V. \& DEMATTÊ, J.A.M. 1991. Parâmetros da rede de drenagem de solos da região de Iracemápolis(SP). Anais da Escola Superior de Agricultura "Luiz de Queiroz", Piracicaba, v.47, pt.2, p.541-545, 1990 .

GROHMANN, F.; RAU, B. van. Influência dos métodos de agitação na dispersão da argila do solo. In: CONGRESSO BRASILEIRO DE CIÊNCIA DO SOLO, 14., 1973, Santa Maria. Anais... Santa Maria : UFSM, 1974. p.123-132.

KOFFLER, N.F. Utilização de imagens aerofotográficas e orbitais no estudo do padrão de drenagem em solos originados do Arenito Bauru. São José dos Campos, 1976, 167p. Dissertação (Mestrado) - Instituto de Pesquisa Espaciais.

LUEDER, D.R. Aerial photographic interpretation: principles and aplications. New York. McGrow-Hill, 1959. 462p.

OLIVEIRA, J.B.; MENK, J.R.; ROTTA, C.L. Levantamento pedológico semi-detalhado dos solos do Estado de São Paulo: quadrícula de Campinas Rio de Janeiro: IBGE. 1979. 179p. (Recursos Naturais e Meio Ambiente, 6).

QUEIROZ NETO, J.P.; JOURNAUX, A. Carta geomorfológica do Vale do Rio do Peixe, em Marilia, Sedimentologia e Pedologia. São Paulo, v.3, n.1, p.10-22, 1978.

RAY, R.G.; FISCHER, W.A. Quantitative photography. a geologic research tool. Photogrammetric Engineering, Washington, v.26, p.143-150, 1960.

STRAHLER, A.N. Quantitative analysis of watersheol geomorphology. Transactions American Geophysical Union Washington, v.38, p.913-920, 1957.

Trabalho entregue para publicaçāo em 17.10.91

Trabalho aprovado para publicaçāo em 05.08 .92 